\title{
EVALUATION AND ANALYSIS OF URMIA LAKE WATER LEVEL FLUCTUATIONS BETTWEN 1998-2006 USING LANDSAT IMAGES AND TOPEX ALTIMETRY DATA
}

\author{
Zahir.Nikraftar ${ }^{\text {a }}$, Ali.Azizi ${ }^{\mathrm{a}}$ \\ a Remote Sensing Division, Department of Surveying and Geomatic Engineering, College of \\ Engineering,University of Tehran, Iran \\ nikraftarz@gmail.com , aazizi@ut.ac.ir
}

KEY WORDS: Urmia Lake, water volume fluctuation, lake shrinkage, critical points, lake area, Salient times

\begin{abstract}
:
The Lake Urmiah has undergone a drastic shrinkage in size over the past few decades. The initial intention of this paper is to present an approach for determining the so called "salient times" during which the trend of the shrinkage process is accelerated or decelerated. To find these salient times, a quasi_continuous curve was optimally fitted to the Topex altimetry data within the period 1998 to 2006. To find the salient points within this period of time, the points of inflections of the fitted curve is computed using a second derivative approach. The water volume was also computed using 16 cloud free Landsat images of the Lake within the periods of 1998 to 2006. In the first stage of the water volume calculation, the pixels of the Lake were segmented using the Automated Water Extraction Index $(A W E I)$ and the shorelines of the Lake were extracted by a boundary detecting operator using the generated binary image of the Lake surface. The water volume fluctuation rate was then computed under the assumption that the two successive Lake surfaces and their corresponding water level differences demonstrate approximately a truncated pyramid. The analysis of the water level fluctuation rates were further extended by a sinusoidal curve fitted to the Topex altimetry data. This curve was intended to model the seasonal fluctuations of the water level. In the final stage of this article, the correlation between the fluctuation rates and the precipitation and temperature variations were also numerically determined. This paper reports in some details the stages mentioned above.
\end{abstract}

\section{1- INTRODUCTION}

The factors that have contributed to the shrinkage of the Lake Urmiah have been well investigated in recent years (Hassanzadeh et al., 2012; Karimi and Mobasheri, 2011; Khatami Mashhadi, 2013; Wurtsbaugh et al., 2014). These influential factors are mainly related to the following causal elements: the drought; the decreased flow of the main rivers of the Lake's drainage basin due to the civil engineering projects such as dam constructions; the change of agricultural crops into those with higher water consumption requirements; bridge construction over the Lake; and increased rate of the drilled water wells. These factors are listed in several investigations as the main causes of the Lake's rapid shrinkage in recent years(Hoseinpour et al., 2010; Zoljoodi and Didevarasl, 2014). However, to reduce further shrinkage progress and to plan the Lake's revival strategies, it is important to determine the precise rate of the contribution of the above mentioned factors. The first stage to achieve this goal is to find out the exact time of the occurrences of the so called 'salient times' within the water level fluctuation time series. These points are regarded as the indicators of the beginning or the terminating phases of an anomaly. These salient points can then be employed to find out the statistical correlation and the contributing rate of the factors that are responsible for the shrinkage of the Lake. The initial intention of this paper is to present an approach for the determination of these salient points. To achieve this, a quasi- continuous curve was optimally fitted to the Topex altimetry data within the period 1998 to 2006 . This portion of the data was selected for detecting the critical points because within this period of time the water level of the Lake has undergone a significant fluctuation rate: The water level of the Lake has decreased rapidly from 1998 to 2002. Within the period of 2002 to 2005 the downward trend of the water level has come to a halt and small increase of the water level is occurred. This is then followed by a downward trend from the year 2006 onward. Fig 1 demonstrates the water level fluctuations within this period of time as compared with the water level fluctuations over a longer period of time.To find the salient points within the period 1998 to 2006, the points of inflections of the fitted curve is computed using a second derivative approach. For a further analysis of the fluctuation rate of the Lake, the water volume were also computed using 16 cloud free Landsat images of the Lake within the periods of 1998-2006. Further analysis on the 
Topex altimetry data is also performed for determining the trend of the seasonal fluctuations of the water level of the Lake which revealed a perfectly sinusoidal variation. These seasonal fluctuations of the water levels may then be compared with the total water level declination. The difference between the seasonal level oscillation and the total water level decline can be interpreted as an indicator that reveals the extent of the contribution of the drought against other influential factors responsible for the shrinkage of the Lake. The sections that follow describe the aforementioned processing stages in some details.

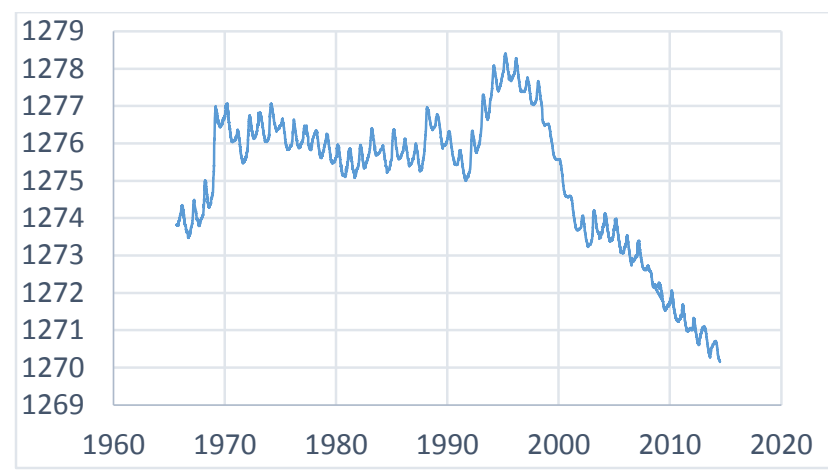

Fig. 1. Water level variations of the Lake Urmiah.

\section{2- LAKE SUFRACE SEGMENTATION APPROCH}

The strategy adopted in this article for the computation of the Urmiah Lake volume change is presented as a flow diagram in Fig. 2. As can be seen in Fig. 2, the first stage of the volume determination process, deals with the segmentation and identification of the pixels belonging to the water body. Varieties of simple indices exist for water feature extraction. The performance of these indices in multi-spectral space depends on several factors such as: image spectral quality, texture variation and the spectral similarities of the features. Using a visual inspection method, the $A W E I$ index for the datasets used in this project indicated to have a better performance as compared with other indices. The AWEI index is given by the following relation (Rokni et al., 2014):

$$
A W E I=4\left(\rho_{G}-\rho_{M I R}\right)-\left(0.25 \rho_{\text {NIR }}+2.75 \rho_{\text {SWIR }}\right)
$$

Where $\rho_{G} ; \rho_{N I R} ; \rho_{M I R}$ and $\rho_{\text {SWIR }}$ denote the green, near infrared; middle infrared and short wave infrared spectral bands respectively. To extract the water feature with $A W E I$, a threshold value is required. An experimental threshold value, $T H R$, is selected based on the visual trial an error approach and binary images are generated accordingly using the chosen threshold value based on the following conditional statement:

$$
\begin{cases}g(x, y)=1 & \text { if } f(x, y) \succ T H R \\ g(x, y)=0 & \text { otherwise }\end{cases}
$$

Where $f(x, y)$ represents the function generated by applying Eq. 1 to the spectral images; and $g(x, y)$ denotes the generated corresponding binary image. In the binary image, the values 0 and 1 denote the lake and the land surfaces respectively.

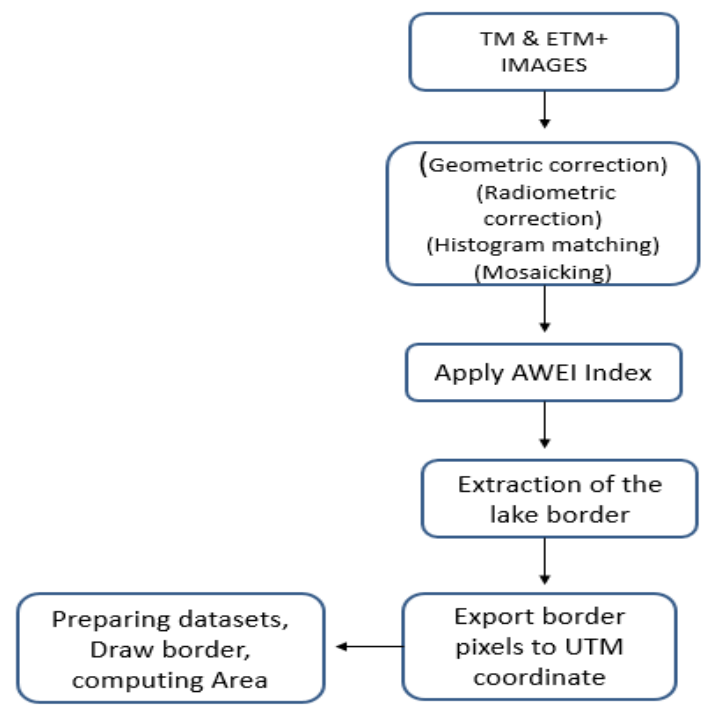

Fig. 2 The flow diagram of the strategy for the Urmia Lake volume determination.

\section{2-2 SHORLINE EXTRACTION METHOD}

To evaluate the adopted approach for the calculation of the area of the surface of the Urmiah Lake, the procedures described in the preceding paragraphs are implemented on 16 Landsat images of the Urmiah Lake acquired between the years 1998 and 2006. The Landsat images were mosaiced so that each image scene contained the entire surface of the Lake. Having generated the binary pixels of the Lake for all 16 Landsat images, a raster to vector conversion procedure is performed to extract the shorelines of the Lake by convolving the binary image with the $2 \mathrm{D}$ template given by the following relation:

$\sum \sum\left\{\left(\begin{array}{ccc}0 & 1 & 0 \\ 1 & -4 & 1 \\ 0 & 1 & 0\end{array}\right) \cdot\left(\begin{array}{lll}g(i-1, j-1) & g(i-1, j) & g(i-1, j+1) \\ g(i, j-1) & g(i, j) & g(i, j+1) \\ g(i+1, j-1) & g(i+1, j) & g(i+1, j+1)\end{array}\right)\right\}$

The extracted shorelines for all 16 Landsat images of the southern parts of the Lake Urmiah are presented in Fig. 3. 


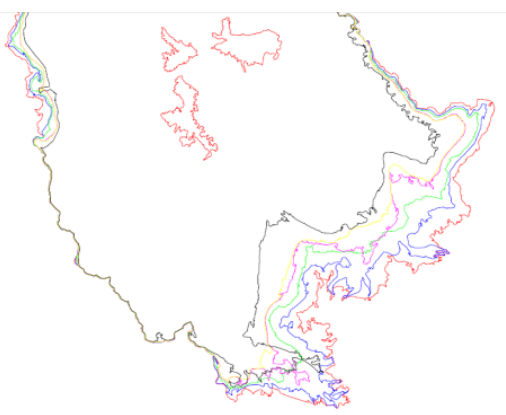

Fig. 3. The southern shorelines of the Lake Urmiahgenerated from the images acquired between the years 1998 and 2001.

Having extracted the shorelines, the area of the Lake is then computed by geo-referencing the extracted shorelines, and a polygonal segmentation scheme is utilized to compute the total area of the surface of the Lake. The computed area in $\mathrm{m}^{\wedge} 2$ for all 16 images together with the acquisition time of each image is given in Table 1. Fig. 4 indicates the Lake area fluctuation as compared with the water level changes.

Table 1. Acquisition time of the images and the computed areas of the Lake surface.

\begin{tabular}{|l|l|r|}
\hline $\begin{array}{c}\text { Data of image } \\
\text { acquisition }\end{array}$ & \multicolumn{1}{|c|}{ Sensor } & Area(m^2) \\
\hline May, 1998 & Landsat 5 TM & 5669756126 \\
\hline November, 1998 & Landsat 5 TM & 5562577181 \\
\hline March, 1999 & Landsat 5 TM & 5282985425 \\
\hline December, 1999 & Landsat 5 TM & 5022956793 \\
\hline February, 2000 & Landsat 7 ETM+ & 4992025258 \\
\hline August, 2000 & Landsat 7 ETM+ & 4765041811 \\
\hline March, 2001 & Landsat 7 ETM+ & 4683501483 \\
\hline June, 2002 & Landsat 7 ETM+ & 4492093064 \\
\hline March, 2003 & Landsat 7 ETM+ & 4361583649 \\
\hline November, 2003 & Landsat 7 ETM+ & 4606234003 \\
\hline March, 2004 & Landsat 7 ETM+ & 4674887881 \\
\hline November, 2004 & Landsat 7 ETM+ & 4463625672 \\
\hline March, 2005 & Landsat 7 ETM+ & 4633254044 \\
\hline November, 2005 & Landsat 7 ETM+ & 4135047076 \\
\hline June, 2006 & Landsat 7 ETM+ & 4425552362 \\
\hline December, 2006 & Landsat 7 ETM+ & 4184722829 \\
\hline
\end{tabular}

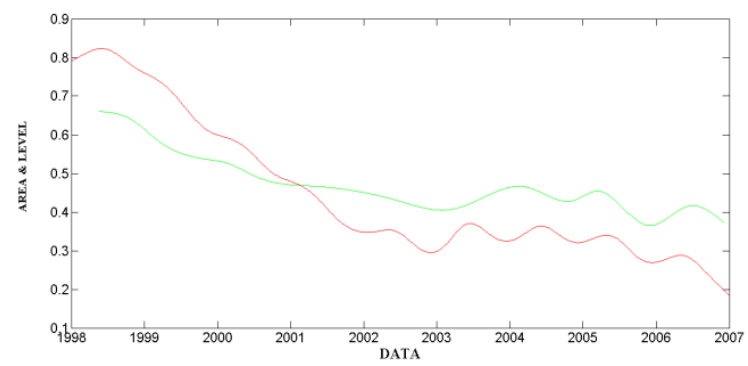

Fig. 4. The computed Lake area fluctuation (Green), water level fluctuation (Read).

\section{2-3ESTIMATION OF THE TOTALL ERRORE ASSOCIATEDWITH THE EREA COMPUTATION}

To estimate the error associated with the Lake area computation, a coastline classification is performed based on the Lake underlying topography. Visual inspection of the extracted shorelines of the Lake in successive images indicated that for those sections of the shorelines in which the slopes were steep, the automatic shoreline extraction was performed with about one pixel accuracy, whereas for low slope parts of the Lake the automatic shoreline extraction had errors more than one pixel. Therefore, based on the coastline underlying slope variation, four classes of slopes were identified (see Fig. 5). Using a visual inspection, estimation was made for the computation of the error associated with each of the coastline zones. A rough estimation of the errors in $\mathrm{km}^{\wedge} 2$ for each of the classified coastline zones and the total error associated with the computed area of the Lake are given in Table 2.

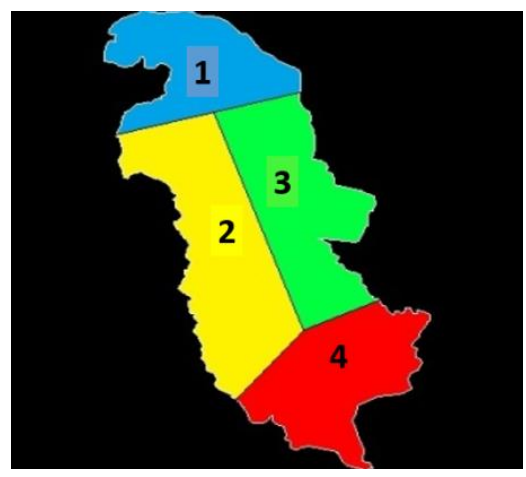

Fig. 5. Coastline classification according to the corresponding shoreline topography.

Table 2. The estimated error for each of the classified coastline zones.

\begin{tabular}{cccccr}
\hline Sections & $\mathbf{1}$ & $\mathbf{2}$ & $\mathbf{3}$ & $\mathbf{4}$ & Total \\
\hline $\begin{array}{c}\text { Error of area } \\
\text { computation }\end{array}$ & negligible & negligible & 2.5 & 5.5 & $\mathbf{8}$
\end{tabular}

\section{3- VOLUME COMPUTATION METHOD}

Regarding the under water topography of the Urmiah Lake which shows linear slopes, a truncated pyramid assumption is adopted for the volume change computation. To compute the volume fluctuations, two consecutive surfaces of the Lake and their water altitude difference are assumed to form a truncated pyramid (see Fig. 6). The volume is then calculated based on the following relation:

$$
V_{H-H^{\prime}}=\frac{1}{3}\left(h-h^{\prime}\right)\left[S+S^{\prime}+\sqrt{S S^{\prime}}\right]
$$

Where $V_{H-H^{\prime}}$ represents the volume of the Lake between two successive water levels; $S$ and $S$ ' denote the area of the 
Lake computed on two successive Lake surfaces. Table 3, Indicates the calculated delta volumes in $\mathrm{m}^{\wedge} 3$ for the image data used in this research.

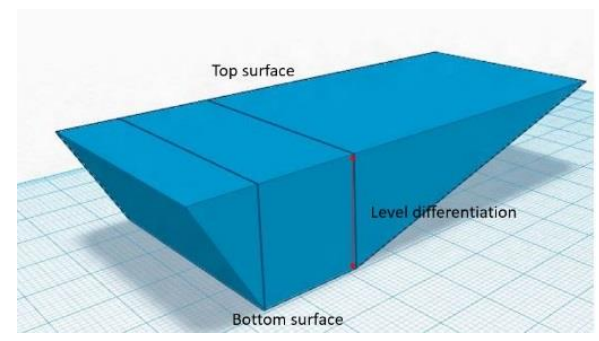

Fig. 6. The truncated pyramid assumption for the water volume fluctuation computation

Table 3. Computed volume change.

\begin{tabular}{|c|c|c|}
\hline $\begin{array}{c}\text { First data of image } \\
\text { acquisition }\end{array}$ & $\begin{array}{c}\text { Second data of } \\
\text { image acquisition }\end{array}$ & $\Delta$ volume(M^3) \\
\hline 1998 MAY & 1998 NOVEMBER & $-3.5 \mathrm{E}+09$ \\
\hline 1998 NOVEMBER & 1999 MARCH & $-6.5 \mathrm{E}+08$ \\
\hline 1999 MARCH & 1999 DECEMBER & $-5.8 \mathrm{E}+09$ \\
\hline 1999 DECEMBER & 2000 FEBRUARY & $9.01 \mathrm{E}+08$ \\
\hline 2000 FEBRUARY & 2000 AUGUST & $-4.1 \mathrm{E}+09$ \\
\hline 2000 AUGUST & 2001 MARCH & $-1 \mathrm{E}+09$ \\
\hline 2001 MARCH & 2002 JUNE & $-4.6 \mathrm{E}+09$ \\
\hline 2002 JUNE & 2003 MARCH & $-4 \mathrm{E}+08$ \\
\hline 2003 MARCH & 2003 NOVEMBER & $6.28 \mathrm{E}+08$ \\
\hline 2003 NOVEMBER & 2004 MARCH & $8.35 \mathrm{E}+08$ \\
\hline 2004 MARCH & 2004 NOVEMBER & $-1.7 \mathrm{E}+09$ \\
\hline 2004 NOVEMBER & 2005 MARCH & $1.55 \mathrm{E}+09$ \\
\hline 2005 MARCH & 2005 NOVEMBER & $-2.1 \mathrm{E}+09$ \\
\hline 2005 NOVEMBER & 2006 JUNE & $9.84 \mathrm{E}+08$ \\
\hline 2006 JUNE & 2006 DECEMBER & $-2.1 \mathrm{E}+09$ \\
\hline
\end{tabular}

The Lake water volume change as compared with the Lake water level fluctuations is given Fig. 7.

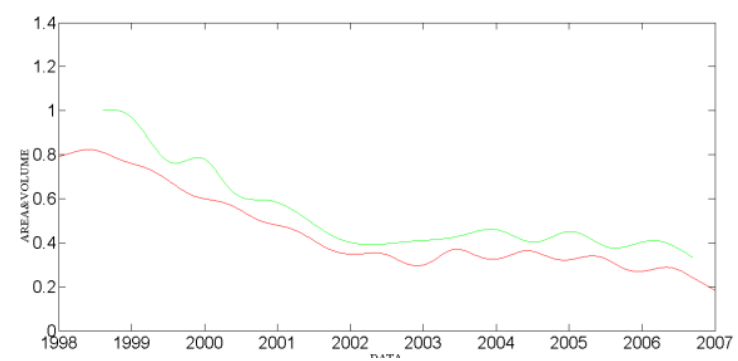

Fig. 7. Water volume change (Green), water level change (Read).

\section{3- DETERMINATION OF SALIENT TIMES FOR THE WATER LEVEL FLUCTUATION}

The data processing parts of the project reported in the previous sections were aimed to determine the area and volume fluctuations of the Urmiah Lake. In this section, the data analysis is presented.

Based on the Topex altimetry data, two distinct water level variations can be identified: (1) the local seasonal changes of the water level, and (2) an accumulating total water level fluctuation. To decompose these two variational components, high order polynomials are optimally fitted to the Topex altimetry data to disassociate the seasonal as well as the random water level oscillations from the total water level variations. The random variation components can be attributed to the random errors (white noise) of the Topex altimetry data. Fig. 8 shows the total water level variations without the presence of the seasonal and random oscillations. The totalfluctuating curve can now be processed for the determination of the salient times. This is achieved by calculating the second derivatives of the curve. The points of inflections, generated by the second derivative, indicate the salient points. The computed salient dates are presented in Table 4.

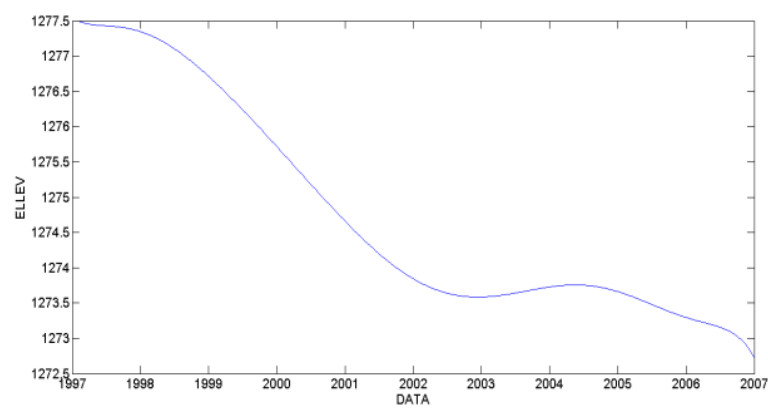

Fig. 8. Extracted total water level changes of the Urmiah Lake for the years 1998 to 2006.

Table 4. Computed salient times.

\begin{tabular}{|c|}
\hline $\begin{array}{l}\text { Dates extracted from the root of the second } \\
\text { derivatives }\end{array}$ \\
\hline $199 \vee / 1 \cdot / \cdot 1$ \\
\hline$r \ldots / / . r / \cdot 1$ \\
\hline$r \ldots r / \cdot q / r V$ \\
\hline$r \ldots o / 1 / / .0$ \\
\hline$r \ldots v / \cdot 1 / r q$ \\
\hline
\end{tabular}

\section{4- COMPUTATION OF SEASONAL VARIATIONOFTHE WATER LEVELS}

The seasonal variations of the water levels are determined by fitting a higher order polynomial function to the Topex data in order to model the quasi-sinusoidal oscillations (see Fig. 9). 


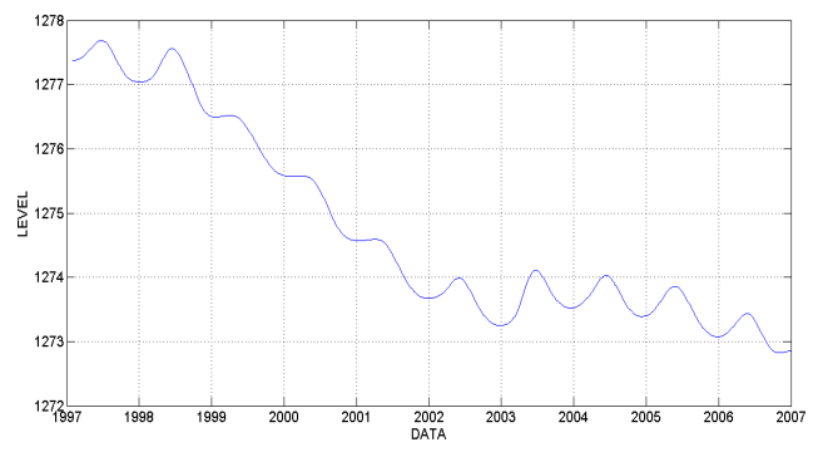

Fig. 9. Urmiah Lake water level total and seasonal variations (1998-2006).

As can be seen in Fig. 9, the random oscillations due to the instrumental noise are eliminated. To produce the pure seasonal oscillations of the water levels, the total fluctuating values (Fig. 8) are subtracted from the Lake total and seasonal water level variations (Fig. 9). The generated function is given in Fig. 10. As Fig. 10 shows the peaks of the seasonal curves mainly coincide with the month of May whereas the minimum water levels coincide with the month of September. Moreover, as Fig. 10 indicates, the points of the minima of the curve are almost stationary, while the peaks of the curve show a gradual declination from the years 1998 to 2002 and a gradual increase from 2002 to 2005 . The local variations of the peaks of the seasonal curves may be partly due to the precipitation and temperature variations and partly due to the reduction of the intake of the Lake from the main rivers due to the agricultural and other consumptions.

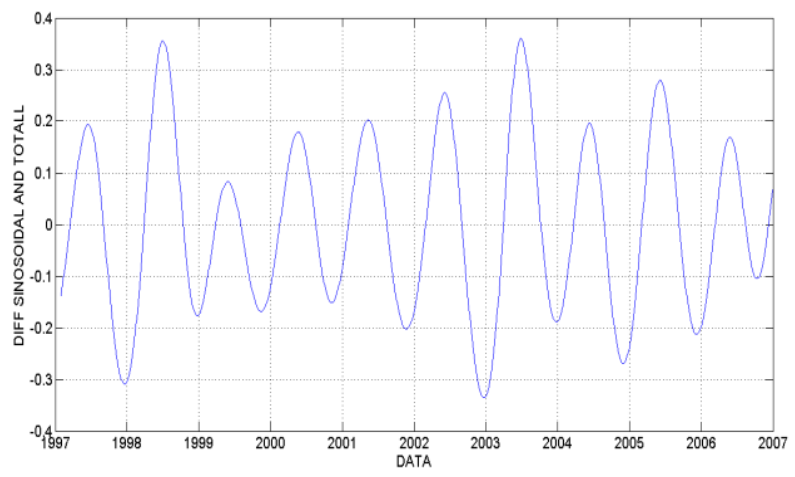

Fig. 10. Seasonal variations of the water level of the Lake Urmiah for the years 1998 to 2006.

To determine the degree of the influence of the precipitation and temperature variations on the water level fluctuations, the precipitation and temperature changes are correlated with the water level changes of the water levels. The scatter plot of the correlation between the precipitation and temperature with the water level oscillations are presented in Fig. 11 and Fig.12 Respectively.

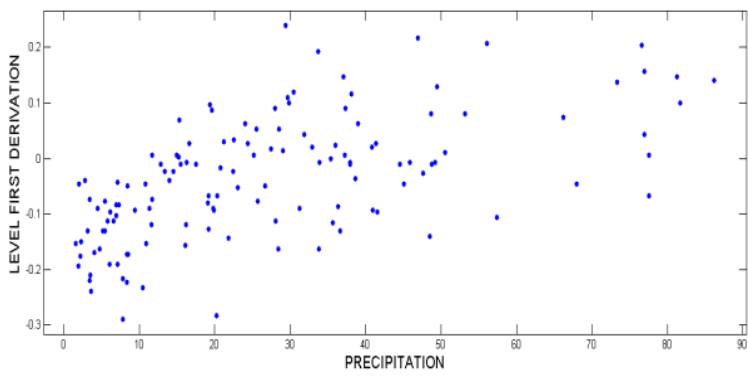

Fig. 11: correlation plot between the precipitation and the water level fluctuation

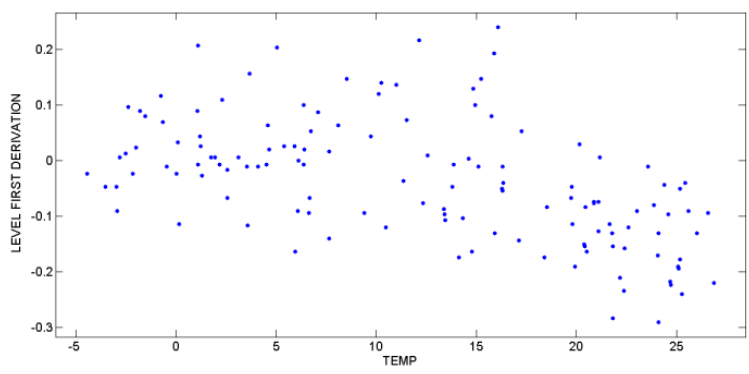

Fig.12: correlation plot between the temperature and the water level fluctuation.

\section{CONCLUSION}

In this article, a method was presented for the computation of the area and water fluctuations of the Lake Urmiah using 16 cloud free Landsat images and the Topex altimetry data. This was followed by presenting a method for the determination of the salient times which can be interpreted as the beginning or the terminating phases of presence of anomalies responsible for the shrinkage of the Urmiah Lake. The effective and optimum strategies for the revival of the Urmiah Lake, demands a precise scrutiny and accurate correlation determination between the Lake water fluctuations and the factors that are responsible for the shrinkage of the Lake. The extension of the analysis presented in this paper may be considered to be beneficial for planning the priorities for the gradual revival of the Urmia Lake.

\section{REFRENCES}

Hassanzadeh, E., Zarghami, M., Hassanzadeh, Y., 2012. Determining the main factors in declining the Urmia Lake level by using system dynamics modeling. Water Resour. Manag. 26, 129-145.

Hoseinpour, M., Fakheri Fard, A., Naghili, R., 2010. Death of Urmia Lake, a silent disaster investigating causes, results and solutions of Urmia Lake drying, in: 1st International Applied Geological Congress, Department of Geology, Islamic Azad 
University, Islamic Azad University-Mashad Branch, Iran.

Karimi, N., Mobasheri, M.R., 2011. Shoreline change analysis of Urmia Lake using multi-temporal satellite images, in: Eighteenth National Conference on Geomatics, Iran, Tehran. Pp. pp. 88-96.

Khatami Mashhadi, S., 2013. Nonlinear Chaotic and Trend Analyses of Water Level at Urmia Lake, Iran.

Rokni, K., Ahmad, A., Selamat, A., Hazini, S., 2014. Water feature extraction and change detection using multitemporal Landsat imagery. Remote Sens. 6, 4173-4189.

Wurtsbaugh, W.A., Marden, B., Micklin, P., 2014. Lake Urmia Crisis and Roadmap for Ecological Restoration of Lake Urmia.

Zoljoodi, M., Didevarasl, A., 2014. Water-Level Fluctuations of Urmia Lake: Relationship with the Long-Term Changes of Meteorological Variables (Solutions for Water-Crisis Management in Urmia Lake Basin). Atmospheric Clim. Sci. 2014. 